\title{
Technology Research Status Review of Long-span Continuous Rigid Frame Bridge Deck Pavement
}

\author{
Hu Wang and Fei Han ${ }^{*}$
}

Department of Science, Chang'an University, Xi'an, Shaanxi, 710064, China

\begin{abstract}
Through the analysis and summary of research status and development trends of deck pavement technology of long-span continuous rigid frame bridge deck pavement at home and abroad, the impact factors of durability of continuous rigid frame bridge deck pavement, such as design flaw, constructional quality and overload are studied. This article will comprehensively analyze the cause of disease focusing on mechanism, structure design deficiency and classification method. Analysis shows that: the durability of continuous rigid frame bridge deck pavement is determined not only by pavement material strength, but also by pavement layer thickness and materials of bridge deck. It is integrated design of pavement and bridge deck, superior construction quality and craft that make sure deck pavement durability. Besides, there are still some imperfections and unreasonableness in existing literatures using finite element calculation of continuous rigid frame bridge deck pavement. In order to provide more credible data for future engineering practice and relevant standard, the finite element method and boundary conditions should be studied and improved.
\end{abstract}

Keywords: Bridge deck pavement, bridge engineering, continuous rigid frame bridge, finite element analysis.

\section{INTRODUCTION}

By the end of the "Twelfth Five-Year Plan", the highway mileage of China has reached 108 thousands kilometers [1]. With the rapid development of urbanization and highway construction, the number of highway bridges have reached 689.4 thousands by the end of 2011. In China, continuous rigid frame bridges which span from 100 to $200 \mathrm{~m}$ are mainly concrete bridges [2]. Girder continuous, pier flexible and pier girder consolidation are the features of continuous rigid frame bridge which have both advantages of continuous girder bridge driving comfortable without expansion joint and $\mathrm{T}$ rigid frame bridge needing no support. In view of this preponderance, continuous rigid frame bridge is widely available, but during the early time of designing bridge structure, relevant industry criteria just considerate deck pavement as secondary dead load imposed on girder. However, bridge structure injury and partial damage on pavement occurred obviously during the serving time, and the damage in girder and pavement has become catastrophic with a surge of traffic and overload vehicle.

In $20^{\text {th }}$ century, developed countries of the west are in the initial stage of large-scale highway construction. Because of incomplete consideration on significance of pavement, heavy maintenance cost was paid during later operational phase of the bridge [3]. Nowadays, many scholars have paid attention to bridge deck pavement and done some researches, but they mainly focus on steel bridge deck pavement: Bild has made a comparatively deep exploration to steel bridge deck asphalt pavement $[4,5]$. Mangus made deep research on bridges in Norway, Russia, Sweden and some other countries, finding that concrete bridge construction had limitations in cold region while steel bridge deck adapted more in this situation [6]. Most designs for concrete bridge deck pavement were based on the concept of bitumen road surface design at home and abroad and lacked pertinent guide or criterion. At present, research result of continuous rigid frame bridge deck pavement is relatively scarce in China; besides, correlational study was just taken partial bridge pavement or pavement material into consideration but did not think of deformation features of continuous rigid frame bridge.

Recent years, Wu Haijun, Zhang Lei and someone else in Chong Qing Jiaotong University have studied the influence of pavement thickness on thermal stress on main girder of continuous rigid frame bridge. Dong Lingyun and the others have done research on asphalt pavement disease of continuous rigid frame bridge. Yun Tao analyzed the law of pavement stress under the function of shrinkage and creep of continuous rigid frame bridge. Luo Jun took bridge deck of continuous rigid frame bridge and deck pavement as the object of study, calculating and analyzing the effect of pavement construction deficiency on pavement stress by building local model with 3D finite element program. Besides, Zhang Jianwei with other researchers in Hebei University of Technology studied the influence rule of overload and thickness of concrete leveling layer on mechanical analysis of pavement by finite element simulation. In view of current researches on continuous rigid frame bridge pavement, this paper will make detailed analysis of continuous rigid frame bridge pavement in aspects of application status, disease type and key mechanism for the formation of disease, existing calculation methods and problems. 


\section{APPLICATION STATUS}

\subsection{Main Types of Disease}

Bridge deck pavement, paved on deck to prevent bridge deck from the wheels or tracks wearing surface directly, is a special type of pavement structure. It can protect girder from rain, distract concentrated load, bear bending moment and resist deformation along with girder. The technical problems of bridge deck pavement have become the key to highway construction technology. As the force situation of deck pavement is different from road [7], the research on deck pavement have been paid more attention in global, and have made great progress. However, when comes to design theory, design criterion, maintenance and detection, there is still existing deficiency. In early years, pavement disease happened soon after being open to traffic, and examples of maintenance costs many times higher than construction exist in engineering widely. In fact, the main types and causes of deck pavement disease are inseparable from bridge construction features, bridge site, construction condition and design level. In America, identification manual of asphalt pavement damage (SHRPP338, 1993) [8] summarized five damage types according to destruction features of deck pavement. They are cracks, patching and pit slots, surface deformation, surface flaw and other mixed damage respectively. Based on the causes of disease of continuous rigid frame bridge pavement, this article will classify these causes into inherent characteristic of structure, insufficiency of structure design and poor construction.

\subsection{Inherent Characteristic of Structure}

As pier and beam are consolidated together, the force bearing status and deformation behavior of continuous rigid frame bridge differ from other bridges. The main distress is concrete crack on top of pier and deflection in midspan of main span. Compared with other type bridge, force status of continuous rigid frame bridge pavement are as follows:

- The negative moment at the pier's top:

Because of pie girder consolidation, the area at the pier's top will occur negative bending moment under vehicle and dead loads action. The maximum negative moment will make deck pavement in region of pier's top bear long-term and repeated tensile stress which could lead to fatigue cracking of concrete pavement [20]. Meanwhile, in view of co-working between bridge deck and deck pavement, interface normal tensile stress between them will happen because of negative moment. The loss of interface cohesive force will directly lead to the damage of bridge deck pavement. Once the contact surface delaminates, pavement will break quickly and even totally destroy.

- The deflection in midspan of beam:

With shrinkage and creep effects of concrete and prestressing loss in steel being aggravated, midspan of existing continuous rigid frame bridge in service will deflect so as to cause inclined cracks in web of beams, which could also bring bad effects to deck pavement.

- Temperature influence:

Bridges are often long term exposure to external environment, and hot-swapping is frequent. Temperature in bridge system is influenced by season exchange, sunshine intensity and other cyclical factors. Cyclical changing temperature may affect elasticity modal of deck pavement materials, especially for asphalt concrete pavement. What's more, it can also lead to a change of temperature gradient, which will cause different degrees of deformation between pavement layer and structure layer. Uncoordinated deformation will ultimately develop into disease.

\subsection{The Flaw in Design}

Pavement design deficiency is often divided into two types: one is insufficient design of structure and another for problematic design and choice of materials.

- The choice of asphalt mixture and waterproof material will directly determine the quality of deck pavement. However, theoretical and experimental study of relevant materials is seldom made during the actual construction process. Poor anti-stripping quality of pavement can lead to water damage. If asphalt concrete material is too soft, disease of rut and upheaval would happen. All of these will finally shorten service life of pavement dramatically [9].

- The insufficient understanding of structure design shows in: only according to the recommended structure and thickness when designing without taking its rationality into consideration. In the early stage of service time of pavement, transverse penetrating cracks and other diseases occur in pier and midspan [9]: Half range of Huang Hua Garden Bridge in the downstream region generated cracks, upheaval, pit slots, and other serious diseases. It is because that the design value of longitudinal slope is $2.5 \%$, in addition, the vehicle speed is slow and drivers shift gears frequently, these finally produce big horizontal braking force in the running process of a vehicle [10]. Literature [11] took Chen Jia Gou Bridge as an example, analyzing and making a conclusion that the thickness of pavement and temperature gradient determined by pavement thickness affect main girder force condition obviously: when the thickness of pavement increases from $5 \mathrm{~cm}$ to $10 \mathrm{~cm}$, the stress variation on upper rim of girder could reach $30 \%$ or even $40 \%$ of the stress caused by lived load with per $1 \mathrm{~cm}$ variation of thickness. Thus it can be seen that enough attention of pavement thickness and girder structure design should be paid during design processes.

\subsection{Poor Construction and Other Reasons}

Despite high-quality materials and reasonable design, the durability of pavement would not be guaranteed without well and strict construction. Typical poor quality construction such as uneven pavement and insufficient strength of concrete will lead to micro cracks or cracks appearing on bridge deck before paving asphalt pavement. These diseases can be found in Stone River Bridge [12].

- Low quality of construction:

Too much concrete slurry and debris of bridge deck were not washed out before paving waterproof layer. Besides, poor construction technology may cause deck elevation 
larger than design value, and then made concrete lift thickness of bridge deck too large or small. The usual construction flaw of deck pavement layer are the following: asphalt concrete quality cannot be controlled at an ideal level. The temperature of asphalt mixture is instable, and roller compaction technology disordered. These nonstandard construction would reduce overall performance of pavement and could cause disease later.

- Careless of daily maintenance:

Not repairing or grouting the cracks of pavement layer in early time and failing to remove sundries from drain pipe will make water accumulating on bridge deck unable to drain [13]. Daily maintenance is indispensible and it directly determines pavement durability.

\subsection{Classification of Disease}

Overall, the difference between asphalt deck pavement and asphalt pavement is that the former is easy to be destroyed by shear stress. Li Mingguo had done research on 87 bridges, and the results showed that $78.1 \%$ diseases of pavement layer are rut, slip and upheaval [14]. Guo Weibin investigated $14952 \mathrm{~m}^{2}$ deck pavement of Foshan Bridge and found that the typical disease of asphalt pavement is rut, upheaval and slip too [15]. Literature [10] compared seven continuous rigid frame bridges whose main span is more than $160 \mathrm{~m}$ in Chongqing, and gave the main type and distribution form of pavement disease of continuous rigid frame bridge in detail.

Crack disease: pavement cracks are mainly divided into transverse crack, longitudinal crack, moved crack and map crack. Once the cracks appear, waterproofness of pavement layer will reduce, what's worse, make steel mesh corroded and coherent layer failed. The appearance of cracks result from synthetical effect of tensile stress in area of midspan and pier, overload vehicle and temperature loads. The main destruction in pavement layer of double-line bridge of Yangtze River Bridge in Chongqing is cracks and loosening. It can be seen from research that there are 48 transverse cracks and $58.3 \%$ concentrate above pier while $25 \%$ appear in midspan. Through research of Huanghuayuan Bridge, there are 43 cracks in half range of Huanghuayuan Bridge, reaching $53.1 \%$ of whole diseases, what's more, $60 \%$ of the cracks is transverse. Crack disease can be seen from Figs. $(\mathbf{1}, \mathbf{2})$.

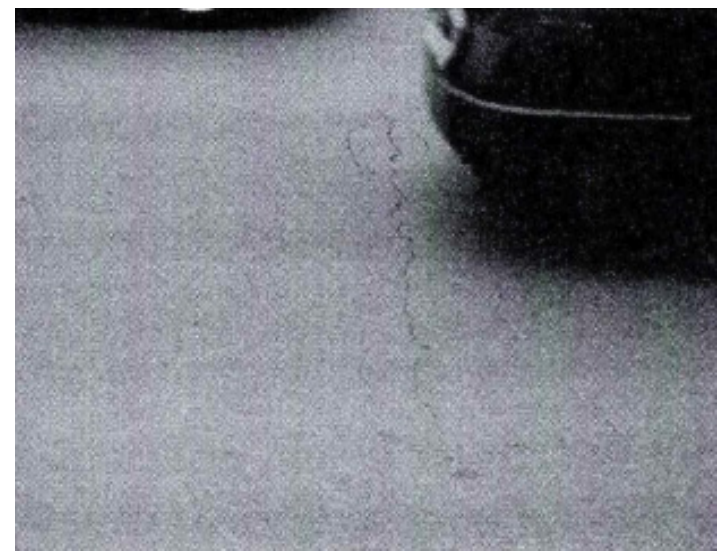

Fig. (1). Transverse crack.

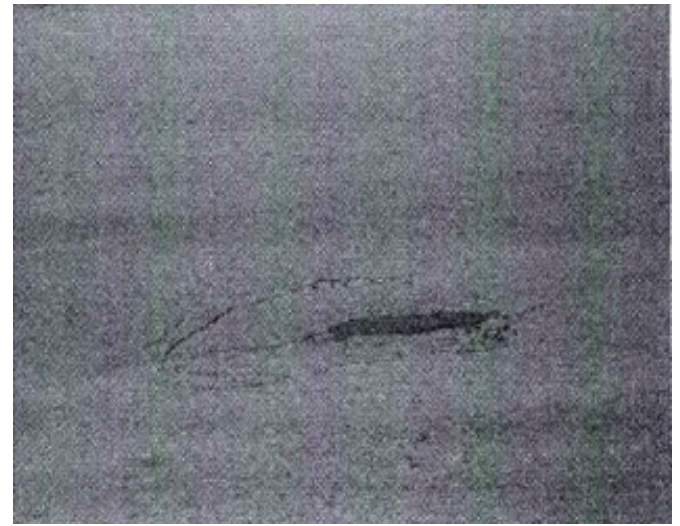

Fig. (2). Moved crack.

Deformation disease: because of plastic flow feature of asphalt concrete, moved disease can be found in asphalt pavement easily. It features undulating waves crossing surface of asphalt concrete. Upheaval is another disease, which is caused by horizontal brake force and vertical wheel load. Its failure mechanism is that the shear stress of structural layer runs over the limit. The rut in half range of Yangtze River bridge Yudong is widely distributed and the longest one exceeds $20 \mathrm{~m}$. The deformation caused by rut is large and distributes mainly around wheelmark. What's worse, the upheaval disease is serious too. The gap between upheavals reduces obviously compared with other bridges. Deformation disease is shown in Figs. $(\mathbf{3}, \mathbf{4})$.

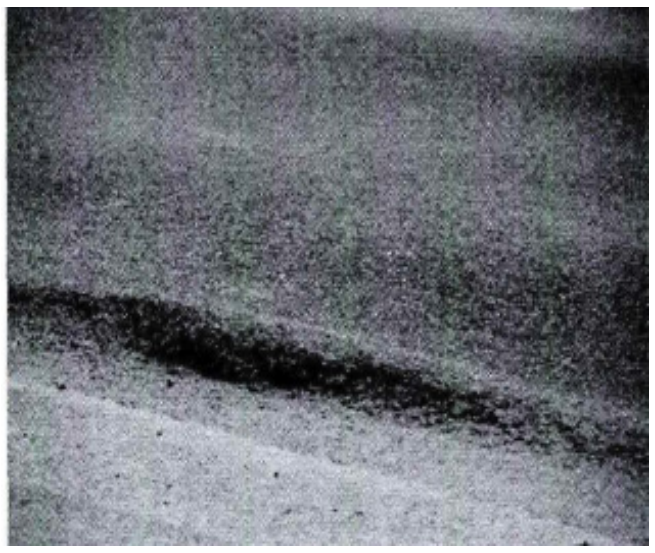

Fig. (3). Rut accompanied by granular loose.

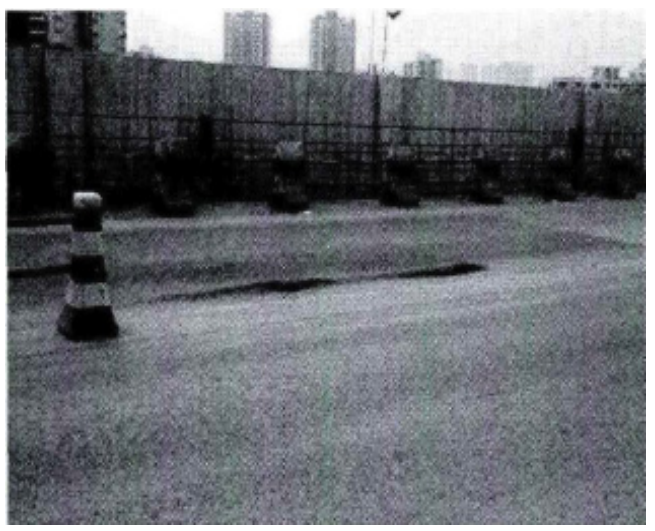

Fig. (4). Upheaval appears again after patching packages. 
Waterproof damage: cohesion failure of waterproof layer is one of the leading types of pavement damage. Bond force is the guarantee of cooperate work between pavement and bridge deck, leveling layer and asphalt pavement layer. An intact bond layer can improve force condition of deck pavement, decrease stress in pavement layer. Once bonding layer destroys, pavement layer will slip and even come off. We can see the disease in Figs. (5 and 6).

Hinge joints destruction: deck pavement repair and maintenance are not well-handled. Diseases like pit and cracks occur in place where the new and old materials are joint after maintenance. Besides, too big vertical impact force caused by bridge bump can also lead to hinge joints damage. This disease is shown in Fig. (7 and 8).

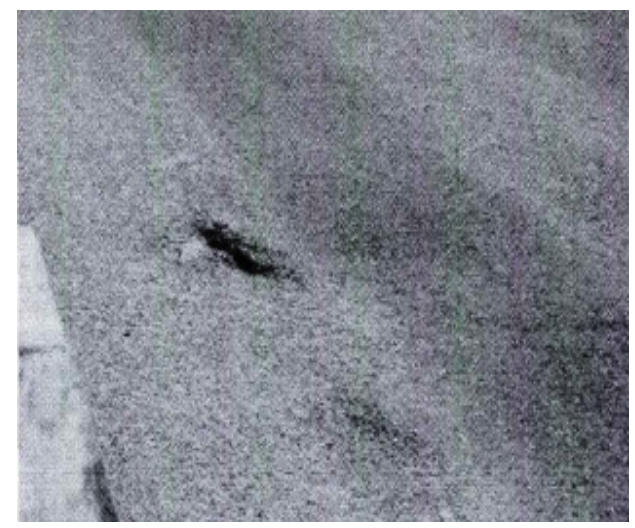

Fig. (5). Disease of pit.

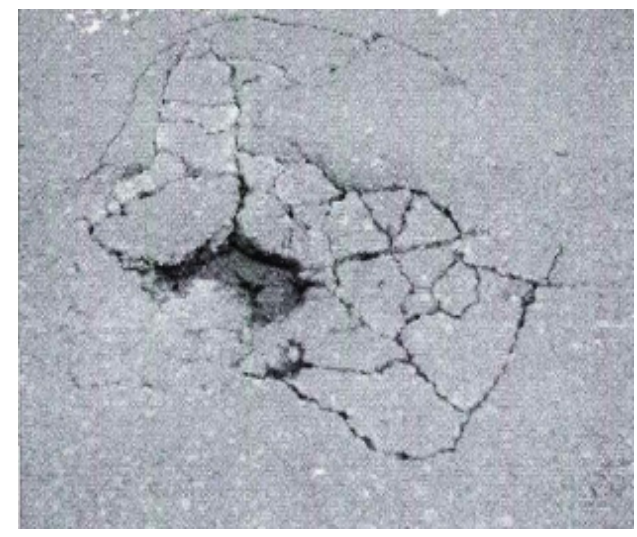

Fig. (6). Disease of pit shedding.

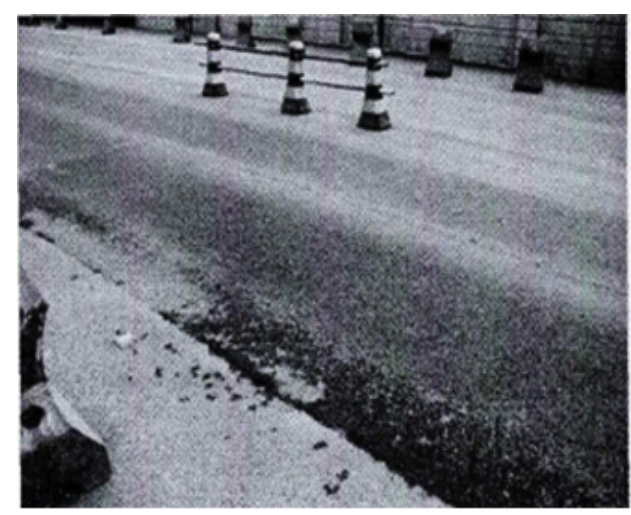

Fig. (7). Waterlogging in longitudinal cracks of pavement.

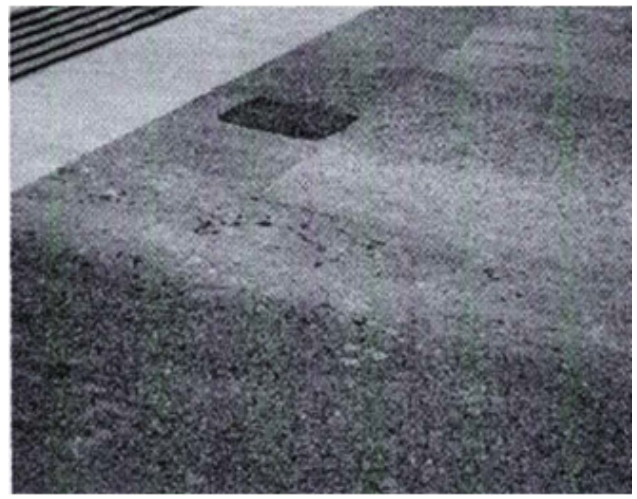

Fig. (8). Ruts and cracks in bridge approach slab.

\section{THE EXISTING METHODS AND CONCLUSION OF CONTINUOUS RIGID FRAME BRIDGE DECK PAVMENT BY FINITE ELEMENT CALCULATION}

\subsection{Choosing a Right Model}

As pavement layer bears vehicle load directly, the stress concentration is distinctly, thus diseases often happen in edge of contact surface of wheels. Because the stress state in pavement layer is complex, it is inaccurate to analyze stress and strain of bridge deck pavement by space beam theory. So we should set up 3D entity model for pavement and beam body.

\subsection{Existing Finite Element Analysis of Pavement}

Reference [16] analyzed the influence law of leveling layer thickness and overload on stress states of continuous rigid frame bridge pavement. In literature, Qijiang Bridge, which thickness of leveling layer and asphalt pavement layer is $5 \mathrm{~cm}$ was studied. And an entire bridge element model was established to get the force situation of the whole bridge. Then, set up local model with 20 meters length of midspan beam segment to calculate the maximum tensile stress in pavement layer in detail. The large finite element program ABAQUS was used in process of local stress analysis, and boundary loads of local model were from the result of entire bridge modeling which used spatial finite beam element method. Concrete material was simulated by 8 node solid elements while prestressed reinforcements by truss element, and prestress was acted by decreasing temperature method. The way of dealing with boundary condition was one end section fixed and another end section formed rigid zone. Then applied the most unfavorable load calculated by entire bridge model on neutral axis. Through simulating and analyzing the impact of overload and leveling layer thickness on pavement stress, it could be concluded that: (1) vehicle overload could make various stresses increase too much in pavement layer and eventually lead to shear and cracking destruction. (2) Leveling layer thickness directly affected stress distribution in deck pavement. If local construction interface existed flaw, the leveling layer should not be too thin. Thus, considering application suitability and economical efficiency, the thickness of leveling layer should not be lower than $8 \mathrm{~cm}$.

Literature [11] studied the impact of pavement thickness on temperature gradient stress of main girder of continuous 
rigid frame bridge. The article pointed that the thickness of asphalt layer was the main factor affecting temperature gradient of main girder. Results showed that the stress at upper edge of main girder caused by temperature difference was obviously bigger than that caused by vehicle load when the thickness of asphalt layer is $5 \mathrm{~cm}$. For every $1 \mathrm{~cm}$ change in asphalt pavement thickness, stress at upper edge of main girder moved $30 \%$ to $40 \%$ of live load stress. During design, it is available to improve stress state of main girder by adjusting asphalt layer thickness.

The influence of shrinkage and creep of long span prestressed concrete continuous rigid frame bridges on deck pavement stress was studied in reference [17]. The paper took Ching River Bridge for example. Firstly it established the whole bridge model by finite element software MIDAS/Civil to calculate creep values at different times. Secondly, extracted creep values corresponding to control section of local model from results. Finally, used ANSYS software to establish local model of pier top and midspan beam section. Besides, displacement boundary condition was chosen for local model: Created mass elements at end section of local model and then used rigid arm to connect mass elements and all nodes on end section, so as to generate rigid surface. Next, took main creep values of control section from MIDAS/Civil as displacement boundary conditions applied on mass elements.

The analysis showed that: (1) The shear stress in pavement layer caused by shrinkage and creep was relatively small, but longitudinal tensile stress was influenced obviously. Pier's top pavement was extremely vulnerable to transverse cracks because the longitudinal tensile stress in pavement layer could reach $0.905 \mathrm{MPa}$ after half a year's running. (2)Tensile stress in pier's top pavement was influenced obviously by shrinkage and creep; however, stress in midspan caused by shrinkage and creep pavement is very small. The stresses of pavement on pier caused by shrinkage and creep can be seen from Table $\mathbf{1}$.

Table 1. Stress of pavement on pier.

\begin{tabular}{|c|c|c|c|c|}
\hline \multirow{2}{*}{ Time/year } & \multicolumn{4}{|c|}{ Pavement layer } \\
\cline { 2 - 5 } & $\mathbf{S}_{\mathbf{y}} \mathbf{( M P a )}$ & $\mathbf{S}_{\mathbf{z}}(\mathbf{M P a})$ & $\mathbf{S}_{\mathbf{x y}}(\mathbf{M P a})$ & $\mathbf{S}_{\mathbf{y z}}(\mathbf{M P a})$ \\
\hline \hline 0 & 0 & 0 & 0 & 0 \\
\hline 0.5 & 0.113 & 0.905 & 0.025 & 0.038 \\
\hline 5 & 0.109 & 0.902 & 0.025 & 0.037 \\
\hline
\end{tabular}

Reference [18] used linear creep theory to analyze creep effect of concrete. Established plane finite element program for creep effect and calculated deflection $y(x)$ in every working condition of bridge. Then used mathematical software Mathematica to fit creep deformation curve with the distance function $h(x)$ from pavement layer to cross-sectional neutral axis. Later, got the relational expression of $y(x)$ and $h(x)$ to calculate normal stress and interface shear stress on pavement layer with material mechanics theory.

\section{1) Normal stress of pavement}

According to "plane cross-section assumption":

$M=E I y^{\prime \prime}(x)$

$$
\sigma=\frac{M}{I} h(x)
$$

So

$$
\sigma=E y^{\prime \prime}(x) h(x)
$$

In equation, $E$ stands for material elastic modal.

\section{2) Interface shear stress analysis}

Take infinitesimal section in longitudinal direction from pavement layer $d x$ to calculate interface stress.

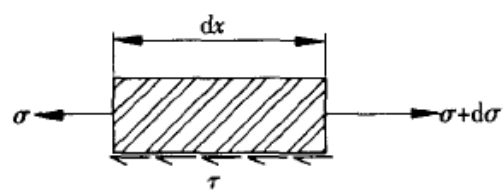

Fig. (9). Free-body diagram of pavement infinitesimal section.

As shown in Fig. (9), $t$ represents for the thickness of infinitesimal section and $B$ for width. By condition of equilibrium, we can write down equation:

$\sigma B t+\tau B t d x=(\sigma+d \sigma) B t$

So:

$\tau=\frac{d \sigma}{d x} t$

And then:

$\tau=\frac{d \sigma}{d x} t=E y^{\prime \prime \prime}(x) h(x) t+E y^{\prime \prime}(x) h^{\prime}(x) t$

Reference [19] studied stress distribution state of asphalt pavement layer when overload acted on continuous rigid frame bridge pavement. According to the literature, firstly it established the whole bridge model by finite element software MIDAS/Civil. Next, calculated internal force of bridge at the most unfavorable load position (midspan and pier's top) by influence-line loading. Unlike reference [17], the boundary condition of local model in this paper was one end fixed. Another end section was not rigid surface but to distribute bending moment, shear force and axial force of entire model equally to each node on end section by equivalent theory of statics. Then, it loaded single, two and three vehicles on pavement layer respectively, calculating the maximum deflection, tensile stress and interface shear stress of pavement layer. The results showed that with the overload degree increasing, tensile stress in longitudinal direction of the bridge surpassed tolerance tensile stress limit. Besides, the maximum deflection value would also increase by increasing overload degree but within allowable range.

Reference [21] set up local model to analyze interface shear stress and tensile stress distribution conditions of continuous rigid frame bridge with construction joints defect and interface bonding flaw between pavement layer and bridge deck. Mainly studied stress distribution states of pavement nearby the defect parts under single heavy vehicle loads. The bottom boundary of model was fixed to simulate the restriction effect by girder, and the model can be seen from Fig. (10). Compared with no construction defect, the inter- 
face shear stress of pavement layer with construction joints is nonnegligible under vehicle loads. Pavement is vulnerable to shear failure and cracking.

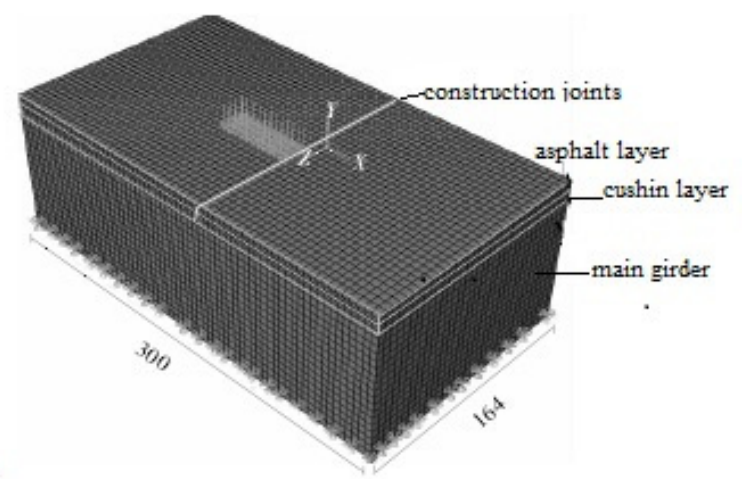

Fig. (10). Finite element model with construction joints.

\section{DEFECTS AND SOME SUGGESTIONS FOR EX- ISTING FINITE ELEMENT CALCULATION}

Literature [16,17] established the full bridge model by MIDAS / civil to calculate the internal force and deformation of the whole bridge, then extracted the internal force and deformation values of node in calculation section of local model under the action of concerned load, fixed one end section of the locality model, and connected all the nodes and mass element on other end by rigid arm to form a rigid surface. Finally, acted force boundary conditions and displacement boundary conditions on mass element. Although it is pointed out in the literature that according to the SaintVenant principle, boundary conditions only affect with a certain range of stress distribution, there are still following problems existing in the partial analysis: (1) in the detailed analysis, stress distribution of different nodes on end section of box girder and pavement is complex and distinctive. Applying the force boundary conditions or displacement boundary conditions separately is less appropriate; (2) the rigidity of the boundary conditions will produce restraint stress in model, especially to internal stress of asphalt pavement. There is no specific analysis in the literature about how much influence of simplification of the boundary conditions on local stress of pavement layer, and what size in the longitudinal direction of local model is appropriate in order to meet the reliability; (3) When acting the stress on local model end section, only apply three internal forces, axial force, shear force and bending moment, produced by longitudinal bending on boundary, and do not consider the influence of horizontal bending moment and torque caused by partial load on pavement layer. The author thinks that more real boundary conditions should be exerted, or before analysis, we should establish the typical model to compare the calculation results of simplified model with the results of real model at the critical position, and then specifically analyze the feasibility of the simplified boundary conditions.

Literature [11] only analyzed the influence of pavement thickness on the temperature stress of the main girder, regardless of the temperature stress distribution principles under the effect of thickness variation in pavement. The temperature field of bridge pavement is the field function which changes along with the time and space. In order to get the temperature stress of asphalt pavement, more detailed temperature monitoring data should be obtained and put into use in model.

There is an assumption in literature [17] that ignores the shrinkage and creep of the pavement and assumes that the deformation boundary conditions of pavement layer and bridge girder are the same. However, compared with girder material, the influence of creep and shrinkage of pavement materials on pavement stresses is more important, and only considering shrinkage and creep effect of girder is less appropriate. In addition, the difference of elastic modulus among asphalt layer, leveling layer and bridge deck is obvious. Besides, the tensile stress and shear stress of pavement layer are proportional to material elastic modulus. So, making the whole end section rigid is unreasonable, and it is difficult to calculate the interface shear stress between the pavement layer and bridge deck.

Compared with literature [17], literature [18] is more reasonable on dealing with the boundary conditions, which considered the variation of pavement creep along the thickness direction rather than exerting the same displacement boundary conditions on both pavement and bridge pavement. The deficiency existing in literature [18] is that the calculation theory adopted can only calculate the normal stress and longitudinal shear stress in pavement, but cannot calculate interface normal tensile stress and transverse shear stress. The calculation theory of reference [18] cannot consider the eccentric load effect and the local effect of wheel load. While under eccentric load, the section of box girder will produce longitudinal bending, torsion, distortion and lateral deflection. Pavement diseases caused by transverse tensile stress and shear stress overrun can not be ignored, so the influence of eccentric load should be considered when analyzing the pavement layer stress. Because the local effect of wheel load function is obvious, the author thinks that the lateral force and stress concentration should be considered meanwhile.

\section{CONCLUSION}

In this paper, research status and development trends of deck pavement technology of long-span continuous rigid frame bridge deck pavement at home and abroad are studied and make some suggestions for existing flaw of calculation method and boundary condition of finite element model. Study shows that:

- Disease of continuous rigid frame bridge deck pavement is not only determined by pavement material strength, but also related to design, construction technology and quality, traffic volume and environment.

- Leveling layer thickness and overloads both affect pavement stress apparently, and the thickness of asphalt pavement is the main factor of temperature gradients effect of main girder.

- Longitudinal tensile stress of pavement is affected by shrinkage and creep of bridge girder obviously especially on the top of pier.

- Construction joints deficiency and interface bonding defect are easy to cause shear failure, tensile failure and pavement void. 
By summarizing and concluding existing research results, the author hopes to find flaws in process of study and offer help and reference to the further research.

\section{CONFLICT OF INTEREST}

The authors confirm that this article content has no conflict of interest.

\section{ACKNOWLEDGEMENTS}

The authors should like to acknowledge with deep gratitude the assistance and guidance given to me by professor Wang.

\section{REFERENCES}

[1] T. Yu, D. Qiao, and Z. He, "Opportunities and bottlenecks of construction of high-grade highways in West China during twelfth five-year period," Journal of Chongqing Jiaotong University, (Social Sciences Edition), vol. 10, no. 4, pp. 11-14, 2010.

[2] X. Gao, X. Huang, and T. Xu, "Mechanical analysis of long-span concrete bridge asphalt concrete deck," Journal of Highway and Transportation Research and Development, vol. 22, no. 1, pp. 7072, 2005.

[3] B. Chen, "Construction Control Studies of Long-Span Prestressed Concrete Continuous Rigid Frame Bridge with High Pier," Beijing: Beijing University of Civil Engineering and Architecture, 2008.

[4] S. Bild, "Durability design criteria for bituminous pavements on orthotropic steel bridge decks," Canadian Journal of Civil Engineering, vol. 14, no. 1, pp. 41-48, 1987.

[5] T. Nishizawa, K. Himeno, K. Nomura, and K. Uchida, "Development of a new structural model with prism and strip elements for pavements on steel bridge decks," The International Journal of Geomechanics, vol. 1, no. 3, pp. 351-369, 2001.

[6] A.R. Mangus, "Orthotropic design meets cold weather challenges: an overview of orthotropic steel deck bridges in cold regions," Welding Innovation, vol. 19, no. 1, pp. 1-7, 2002.

[7] T. Xu, "Study of Long-Span Concrete Bridge Deck Pavement," Nanjing: Nanjing University, 2003.
[8] L. Zhang, and J. Mou, "The project design and experimental research of Steel bridge deck pavement," Highway, vol. 1, no. 1, pp. 28-32, 2001.

[9] L. Dong, Z. He, and T. Yu, "Damage investigation and analysis on asphalt concrete deck pavement of large span continuous rigid frame bridge," West China, vol. 52, no. 11, pp. 38-41, 2011.

[10] T. Yu, "The Mechanical Analysis and Rational Construction Research of Long-Span Continuous Rigid Frame Bridge Deck Pavement," Chongqing: Chongqing Jiaotong University, 2012.

[11] H. Wu, L. Zhang, P. Lu, and Z. Zhou, "Effect of asphalt bridge deck pavement depth on beam temperature gradient stress of continuous rigid frame bridges," Journal of Chongqing Jiaotong University, vol. 30, no. 1, pp. 30-34, 2011.

[12] S. Guo, "Concrete pavement failures and repair measures of Jingqin highway," Transport Word, vol. 1, no. 15, pp. 74-75, 2009.

[13] Y. Yu, "The Forced Mechanism of Cement Concrete Bridge Deck Pavement," Chongqing: Chongqing Jiaotong University, 2004.

[14] M. Li, "Structure Analysis and Material Optimization for Concrete Beam Bridge Asphalt Mixture Deck," Xi'an: Chang'an University, 2010.

[15] W. Guo, "Deck pavement failure and rebuilt technology of Foshan Bridge," Guangdong Gonglu Jiao Tong, vol. 45, no. 4, pp. 14-17, 1996. (in Chinese)

[16] J. Zang, Z. Pan, and J. Luo, "Effect of overloading and the leveling layer thickness on deck pavement stress of continuous rigid frame bridge," Journal of Chongqing Jiaotong University, vol. 32, no. 6, pp. 32-35, 2013

[17] T. Yu, Z. He, X. Chen, and L. Dong, "Stress analyses on bridge deck pavement of continuous rigid frame bridge with shrinkage and creep," Journal of Chongqing Jiaotong University, vol. 31, no. 5, pp. 31-35, 2012.

[18] X. Liu, G. Wang, C. Wei, and Y. X. Ou, "Stress analyses on bridge deck pavement of long-span concrete bridge with shrinkage and creep," Journal of China \& Foreign Highway, vol. 26, no. 3, pp. 141-143, 2006.

[19] X. Guo, "Linear and Nonlinear Mechanical Analysis on Asphalt Concrete Bridge Deck Pavement of Continuous Rigid Frame Bridge," Beijing: Beijing Jiao tong University, 2014.

[20] J. Zhang, "The analysis and measures to the diseases of pavement at the top of pier," Highways \& Transportation in Inner Mongolia, vol. 1, no. 2, pp. 64-66, 2014.

[21] J. Luo, X. Huang, Z. Pan, and J. Zang, "Mechanical influence of bridge pavement construction defects on deck pavement," Journal of Chongqing Jiaotong University, vol. 33, no. 3, pp. 22-26, 2014.

Received: May 26, 2015

(C) Wang and Han; Licensee Bentham Open.

This is an open access article licensed under the terms of the (https://creativecommons.org/licenses/by/4.0/legalcode), which permits unrestricted, noncommercial use, distribution and reproduction in any medium, provided the work is properly cited. 